\title{
Cumulative Trauma Disorder Scale (CTD): Two Studies
}

\author{
Ibrahim A. Kira ${ }^{1}$, Thomas Templin ${ }^{2}$, Linda Lewandowski ${ }^{2}$, Jeffery S. Ashby ${ }^{3}$, \\ Alwande Oladele ${ }^{4}$, Lydia Odenat ${ }^{5}$ \\ ${ }^{1}$ Center for Cumulative Trauma Studies, Stone Mountain, USA \\ ${ }^{2}$ Wayne State University, Detroit, USA \\ ${ }^{3}$ Georgia State University, Atlanta, USA \\ ${ }^{4}$ DeKalb County Board of Health, Decatur, USA \\ ${ }^{5}$ Emory University, Atlanta, USA \\ Email: kiraaref@aol.com
}

Received June $10^{\text {th }}, 2012$; revised July $8^{\text {th }}, 2012$; accepted August $9^{\text {th }}, 2012$

\begin{abstract}
Measures that screen for mental health in multiple traumatized populations (e.g., refugees, minorities, mental health patients, prison inmates) lack theoretical clarity that makes it difficult to develop a measure that has robust psychometrics. The paper proposes cumulative trauma disorders (CTD) model and develops a scale that measures the concept and can be used as a general mental health screening tool in such populations. The measure has been tested on two studies: on representative community sample of Iraqi refugees in Michigan and on a clinic sample of refugees. Further, the measure was used on samples of Iraqi refugee and African American adolescents, West Bank and Gaza in Palestinian territories, as well as a mental health screening tool in some centers that screen refugees and torture survivors in US. The measure has been found to have high alpha and test-retest reliability, good construct, concurrent, discriminative and predictive validity in the two main samples and on all the studies and centers that utilized it. The measure can be used as a general mental health screening tool for adult and adolescent in public health settings in different cultures, as well as for refugees, torture survivors, and highly traumatized populations.
\end{abstract}

Keywords: Complex PTSD; DESNOS; Cumulative Trauma Disorders (CTD); Torture Survivors; Refugees; Minorities

\section{Introduction}

There is an intricate divide between three major paradigms in studying traumatic processes: the psychiatric paradigm that focused mostly on the physical survival types of traumatic stress and on post-traumatic stress disorder (PTSD) model (e.g., van der Kolk, Weisaeth, \& van der Hart, 1996), the psychoanalytic, and developmental paradigms that focused more on studying the effects of abandonment, early childhood and betrayal traumas (e.g., Bowlby, 1988; Cassidy, \& Shaver, 1999; Freyd, DePrince, \& Gleaves, 2007), and the intergroup paradigm as evidenced in studying discrimination, genocide, torture and other shared politically motivated micro and macro aggressions (e.g., Pieterse, Todd, Neville, \& Carter, 2011; Kira et al., 2008, 2010a; Kira et al., 2010b; Williams, \& Mohammed, 2009; Perez, Fortuna, \& Alegría, 2008). All the three paradigms found severe physical and mental health consequences for the trauma types that were the focus of their studies. Integrating these three paradigms should help advance trauma theory and research.

There are at least two problems with the current status of trauma theory. The first is its fragmentation that does not allow for a comprehensive trauma assessment that evaluates the traumatic exposure of the individual; second it is more focused on past traumatic events, commonly ignoring the present ongoing and those continuous traumatic stressors. The focus on the past traumas only is unfortunate because it tends to obscure the dynamics of the ongoing traumatic events that have unique effects that may modulate, add to or amplify the effects of the past traumas. A new developmentally based traumatology framework (DBTF) integrated these three main streams (the psychiatric, the psychoanalytic, and the intergroup) in a unified development-based traumatology perspective and developed its measurement tools that help map their profiles (e.g., Kira, 2001, Kira et al., 2008, Kira, Templin et al., 2010). Kira (2001), and Kira et al., 2008), proposed a two-way taxonomy of traumatic stressors that is theoretically plausible and empirically-supported and provides wider and defined boundaries of what are traumatic stressors and their cumulative dynamics. The first dimension of DBTF is development-based and includes attachment traumas (e.g., abandonment by parents of a child), identity traumas that has at least three kinds: personal identity trauma, (e.g., violation of self autonomy by rape, sexual or physical abuse, incest and other betrayal traumas), and collective identity or shared trauma, (e.g., targeted genocide, holocaust, slavery and discrimination), and role identity or self-actualization trauma, (e.g., loss of life-savings, failed business, get unexpectedly fired, failed or dropped out of school or college). Additionally the taxonomy, at this dimension, includes interdependence, secondary or indirect trauma, (e.g., witnessing violence or media relevant violence exposure or compassion fatigue of therapists), and physical survival, e.g., life threatening accident, or major natural disaster, assault and combat. The new trauma framework includes varieties of traumas and trauma profiles that the individual may suffer and their collective effects together never been considered. The second dimension in DBTF describes the level of severity and chronicity. 
Traumatic events may include, at least two kinds: single episode trauma (type I) (e.g., car accident) and complex traumas. Complex traumas, in terms of chronicity, include two kinds: type II (repeated similar traumatic episodes that ceased, for example sexual abuse) (see Terr, 1991), and type III (continuous, repeated and ongoing, e.g. racism). Examples of continuous chronic personal identity traumas are prostitution and trafficking. Example of continuous collective identity traumas is protracted conflict and related terrorism and other forms of intergroup violence. Type IV, in this taxonomy, is cumulative trauma (CT) across life time and include the past and those different ongoing traumas and have different cumulative dynamics.

Varieties of trauma profiles that include similar or dissimilar, past, present and continuous traumas, potentially set off related clusters and profiles of cumulative trauma related disorders CTD (Kira, 2001; Kira et al., 2008; Kira, 2010; for definition of CTD, see Kira et al., 2008). Related CTD models, that are defined based on clinical and empirical data, may have better utility and clinical validity than comorbid diagnoses. Each of the diagnoses may capture an aspect of the traumatized individual's experience, but frequently does not represent the whole picture of the impact of the cumulative traumatic violence (Cook et al., 2003).

Further, because of the comorbidity and overlap between diagnostic categories, epidemiological research often describes rates of common mental disorders as a single outcome (e.g., Tyler, 2001). Grouping of all comorbid disorders under the rubric of common mental disorders (CMD) have a clear public health utility in mapping symptom or syndrome profiles.

Different CMD models and symptom profiles are emerging to describe the actual impact of different profiles of cumulative traumas. DESENOS (Disorder of Extreme Stress Not Otherwise Specified) model suggested by Herman, 1992, is an example of such evolving models that describe symptoms that resulted either from prolonged sexual abuse or incest and/or war traumas. DESENOS symptom profile includes a) extreme affect and impulse dysregulation (e.g., rage, suicidality, selfdestructiveness, and non-modulated sexual activity); b) pathological dissociation; c) somatization (including alexithymia); and d) fundamentally altered beliefs concerning self and relationships. However, the DESNOS model, while it is valid for complex traumas such as child sexual abuse and incest, fails to account for the full spectrum of symptoms presented by other trauma profiles, for example, in refugees and torture survivors. While complex PTSD or DESNOS symptom profile is observed when the individual experiences the same traumatic situation repeatedly over prolonged periods of time, for example in sexual abuse, CTD can occur when the individual experiences a sequence of similar or dissimilar kinds of traumas over life time.

Conversely, the cumulative trauma disorders (CTD) model, presented here and elsewhere (Kira, 1999, 2001, 2010; Kira et al., 2008) is a different model that can describe the post cumulative trauma symptoms in multiply traumatized populations based on theory and established etiology. Cumulative trauma and cumulative trauma related disorders may be relevant to this presentation as well (e.g., Cloitre et al., 2009). The following clinical case example illustrates the acute sudden response to type IV or cumulative trauma.

"Fatima (pseudo name) is a 55-year-old Iraqi refugee and is a divorced woman. She has lived in Michigan for six years. She has 9 living children, 4 boys and 5 girls, ranging in age from 10 to 25 years. In Iraq, she lost two brothers and two sons who had been killed by the regime. She witnessed the killing of one of her sons and the other family members who were killed. She remembers each one was brought soaked in blood, into the house. Each had to be buried without a funeral. Moreover, the family had to pay for the bullets that killed them. After the failure of the uprising against the regime in 1991, she had to flee, walking in the desert for days with her immediate family to Saudi Arabia. She spent 4 years in a refugee camp in the desert. She remembered the suicides in the camp, violent killings of those who rose up against the repressive authorities who ran the camp. She remembers the isolation and desert tornadolike sand storms. When she came with her family to the USA, she had to deal with a different set of traumas; among them were her husband's infidelity and physical abuse. She divorced him. The first author knows her because one of her sons, a seven year old at the time, hears trauma congruent and non-congruent voices, has nightmares, and other CTD symptoms. All her family members describe her as the heroine of the family whose personal resiliency helped her survive all these traumas, as well other traumas not mentioned here. Her functioning remained intact and presented no symptoms. Two years after the start of therapy with her son, her daughter was driving a car, in which she was a passenger. She got involved in a moderate car accident that resulted in some bruises for her and for her daughter. After this car accident, Fatima started to develop serious symptoms of fears, panic attacks, auditory and visual hallucinations, and nightmares congruent and sometimes non- congruent with the terrors she had experienced before, but not related to the car accident".

In this clinical vignette, the client survived a series of severe traumas that have cumulative effects, and the last, which probably may have been the least severe, acted as "the straw that broke the camel's back". Such example gives credibility to the concept of cumulative trauma and CTD.

\section{The Symptom Clusters of CTD in Refugees and Torture Survivors}

Based on clinical observation and previous studies, CTD potential symptoms profile in torture survivors and refugees, the focus of these studies, includes:

a) Positive symptoms: e.g., trauma congruent and non-congruent auditory and visual hallucinations. Our clinical observation and previous findings acknowledged the prevalence of such symptoms in refugees, torture survivors and other survivors of cumulative trauma without giving them serious consideration in the assessment (e.g., Werbert \& Lindbom-Jakobson, 1993; Pinto \& Gregory, 1995; Patrick, 1995; Holmes \& Tinnin, 1995, Wenzel, Sibitz, Kieffer, \& Strobl, 1999).

b) Negative symptoms: apathy, affective flattening, avolition, anhedonia, and social withdrawal, (cf. Stampfer, 1990), and impaired emotional processing (e.g., Rachman, 1980; Fao, 1996). Research provides evidence that torture is an important predicttor of emotional withdrawal (e.g., Larik, Hauf, Skrondal, \& Solberg, 1996).

c) Cognitive deficits, such as impaired concentration, memory and executive functions (e.g., Sutker, Vasterling, Brailey, \& Allain, 1995).

d) Mood disorders that include depression, anxiety comorbidity, suicide and suicide tendencies/ideation, hopelessness, an- 
xiety, agitation, and hostility, simple PTSD symptoms, and other symptoms of impaired mood.

e) Identity disorders, e.g., dissociation and somatization, sleep disorders, impaired future orientation (stuck in the past), and impaired interpersonal relations and social functioning. It can cause suicide or self-injurious behavior or physical violence attitude toward children, women or family.

f) Substance abuse problems. For example, higher levels of acculturative stress found to be positively associated with increased prevalence of polysubstance abuse (Arfken, Kubiak, \& Farrag, 2009) Substance abuse can be attempts to self-medicate.

\section{Mental Health Screening Tools for Refugees and the Highly Traumatized Populations}

There is paucity of valid and reliable screening mental health measures that screen multiply traumatized populations, (e.g., refugee, minorities, prison inmates) and map symptom clusters associated with different cumulative trauma profiles, based on valid empirical and theoretical basics. The need for culturallyvalid screening instrument for CMD or CTD has been particularly important for screening in general practice.

World Health Organization WHO, 1994, developed a selfreporting questionnaire of 20 questions (SRQ-20) as a screening tool to detect CMD in primary healthcare attendees in lowincome countries. Several versions of the Self-Reporting Questionnaire (SRQ) were used as a practical screening and research instruments for the detection of psychiatric morbidity across different cultures and populations (e.g., Scazufca et al., 2009). SRQ is not based on empirical or theoretical analysis of cumulative trauma symptoms in the targeted populations. SRQ-20 was criticized, as it includes only symptoms related to anxiety and depression. The mood, neurotic and psychotic disorders are also common and there is a noticeable overlap of symptoms of depression, anxiety, fatigue, or somatic complaints in CMD. Different versions added other items that represented psychotic symptoms (e.g., Youngmann et al., 2008). Psychiatrists recently recognized the problem of diagnostic heterogeneity in applying measurement-based care in clinical practice and suggested the concept of psychiatric vital signs (e.g., Zimmerman, Young, Chelminski, Dalrymple, \& Galione, 2012).

One of the measures' were suggested and used widely with refugees and torture survivors, is Harvard trauma questionnaire (HTQ) (e.g., Mollica et al., 1992). HTQ, is a good tool for measuring some syndromes, but not designed to be a comprehensive screening tool. Some critiques that targeted early SRQ versions apply to (HTQ), as it does not measure, for example dissociation psychosis and other mental health syndromes present in multiply traumatized populations.

The goal of this paper is to utilize the DBTF framework and the concept of CTD to develop and test a general screening tool for CTD or CMD in refugees, torture survivors and minority populations that is comprehensive, theoretically plausible and empirically valid. We conducted two initial studies, followed by other different studies on different populations and cultures. The first was on a clinic sample of 286 mental health clients some of whom went through torture, the second (501 Iraqi) was on a community sample of Iraqi refugees in Michigan USA.

One of the rules we adopted in designing the CTD screening measure was to use the least number of questions that address all the six clusters. Measures addressing highly traumatized populations should use brief measures, as attention span may be limited. Long questioning can cause high rate of missing and unreliable data. For example, Chochinov et al., 1997 in a study on terminally ill subjects (highly traumatized) found that a single item measure of depression had more predictive power of depression diagnosis than longer measures of depression. Short measures in highly traumatized can be at least as reliable and predictive.

\section{The First Study}

\section{Method}

\section{Participants}

The participants were all adolescent and adult clients requesting services in a mental health clinic during three consecutive months (January, February and March, 2002). The one on one interviews were part of the routine assessment for all clients: $(\mathrm{N}=286$, mean age $=39.97, \mathrm{SD}=13$, minimum $=12$, maximum $=69$ ). Most of the participants were Arab Americans immigrants and Iraqi refugees. They included $60.1 \%$ Iraqi, 19.8\% Lebanese, $10.1 \%$ Yemeni, $6.9 \%$ other Arabic, and $6 \%$ non-Arabic. They included $36.6 \%$ American citizens, $15.5 \%$ legal residents, and $47.8 \%$ refugees. From participant, $8.2 \%$ stayed in US from 1 to 3 years, $23.4 \%$ stayed in US from 4 - 7 years, and the rest stayed either more than 7 years or born in the country. For education, $24.2 \%$ were illiterate, $64.9 \%$ had high school education, $5.6 \%$ have college education, and $5.2 \%$ have or studying for graduate degrees. For marital status, $71.4 \%$ were married, $20.9 \%$ were single, $5.6 \%$ were divorced, $1 \%$ was widows, and $1 \%$ had other marital statuses. For income, $95 \%$ had yearly income of $10.000 \$$ or less, the rest reported 10.000 to 20.000 of yearly income. Their ages ranged between $12-69$, with $38.4 \%$ males and $61.6 \%$ females. Fourteen percent of the respondents $(30 / 215)$ reported that they were jailed and tortured. Twenty-four of the tortured were males and 6 were females, 27 of the tortured were Iraqis and 2 were other Arabic. The gender differences between tortured and non-tortured were significant with more males reporting torture; however the differences in ethnicity, diagnosis, employment status and education were not significant.

\section{Measures}

The Cumulative Trauma Disorders (CTD) measure. The cumulative CTD measure was developed according to the operational definition of the concept previously discussed. A pool of 39 items that represent the identified 13 symptoms were further screened by focus group of 5 professionals to chose the least number of items that represent the symptom clusters. Initially 13 items were chosen (in the current study), but subsequent studies and analysis ended up in dropping two items and adding new five items to have a 16 items scale (see Appendix). For each item, client was asked to identify on a five-point scale $(0$ - 4) the degree he/she experienced the symptom: (0) Does not Apply, (1) I am not sure, (2) Some what present, (3) Much Present, (4) Very Much Present.

Stigma Consciousness Questionnaire (SCQ) for mental health patients. A modified version of Stigma Consciousness Questionnaire (SCQ; Pinel, 1999) was used. This 10-item selfreport inventory is rated on a 7-point Likert scale ranging from strongly disagree (1) to strongly agree (7). The SCQ can be adjusted for use with any stigmatized group by inserting the proper names of the in-group (stigmatized group) and the asso- 
ciated out-group in question. Sample items include: "Most Americans have a problem viewing mental health consumers as equals" and "Stereotypes about mental health consumers have not affected me personally" (reverse scored). A mean score for stigma consciousness was generated with higher scores indicating an increased sensitivity in one's perception of discrimination and prejudice related to their stigmatized status (greater stigma consciousness). Pinel (1999) demonstrated construct validity of the SCQ by correlating it with previously established assessments of public and private self consciousness, social anxiety, and trust in others. There is no existing research that uses mental health -based version of the SCQ. In the current study, the SCQ was found to have adequate internal consistency (.75).

Socio-demographic questionnaire and information about torture and jail and other information, such as primary and secondary diagnoses, the client is on Psychotropic medication or not was also collected from the clinical files.

\section{Procedures}

Subjects were interviewed face to face in a private room by a bilingual clinician as part of a comprehensive assessment upon intake. Responses were recorded by the interviewer with confidentiality being emphasized. HIPPA and other informed consent forms were provided and signed by client and/or his/her guardian. Data entry was performed by trained bi-lingual clinic staff.

The measures in current and subsequent study were translated into Arabic by three bilingual mental health professionals, each individually translating the measures and then meeting together to establish a consensus on the final version based on the criteria of adequate cultural sensitivity and appropriateness in measuring the construct of the instrument. A fourth mental health professional did the reverse translation. These measures were pilot tested in focus groups.

\section{Data Analysis}

Data analysis was performed using SPSS 11.5 and AMOS 7.00. Item and scale as well as test-retest reliability analyses were conducted for the CTD measure. Exploratory and confirmatory factor analysis was conducted to test the psychometric validity of the measure. Correlations was calculated between CTD scale, its sub-scales, and torture, stigma consciousness, being on psychotropic medications, and having primary diagnosis to establish the predictive and convergent validity of the scale.

\section{Results}

Principal component factor analysis using the scree test (Cattell, 1966), Kaiser Criterion eigenvalue greater than one (Kaiser, 1960), and Oblimin rotation, yielded four factors accounting for $71.65 \%$ of the variance. The first factor loaded high on items of concentration and memory deficit, self-control of reactions, and avoiding people. We labeled this factor " $E x$ ecutive function deficits". The Second factor loaded high on suicidality and hurting self and labeled "Suicidality". The Third factor loaded high on dissociation, hearing voices and paranoid ideations and labeled "Dissociation/Psychosis". The Fourth factor loaded high on depression and anxiety and labeled "Depression-Anxiety comorbidity" Table 1 describe this structure.

Confirmatory factor analysis: The subscale structure identified in the exploratory analysis was generally consistent with the literature and with clinical conceptualization of personality functioning from a variety of theoretical perspectives. This simple structure solution suggests four conceptually distinct factors each defined by two, three, or four items. To examine the latent structure among these four dimensions, a confirmatory factor analysis of the inter-item covariance matrix was conducted. A third order CFA was specified using the obtained simple structure results and theory. All but one of the thirteen items was retained in the final model. The omitted item, "I try to avoid people and stay by myself" resulted in poor fit due to

Table 1.

Factor loadings for the four factors solution of CTD scale.

\begin{tabular}{|c|c|c|c|c|}
\hline & \multicolumn{4}{|c|}{ Component } \\
\hline & 1 & 2 & 3 & 4 \\
\hline I have problems in concentration and memorizing & .84 & -.09 & .02 & -.09 \\
\hline I do not feel that I have enough control on my responses and reactions & .80 & .09 & .09 & -.04 \\
\hline I feel too harsh on my family, e.g. children & .70 & .18 & -.13 & .16 \\
\hline I feel too harsh dealing with people in general & .52 & .20 & -.16 & .33 \\
\hline I try to avoid people and stay by myself & .50 & -.12 & .22 & .37 \\
\hline Sometimes I feel like hurting myself & -.05 & .95 & .05 & .01 \\
\hline Sometimes I feel suicidal & .08 & .92 & .09 & -.06 \\
\hline I sometimes feel if I am almost two different people & .03 & .03 & .82 & .01 \\
\hline I believe I have enemies that follow me anywhere I go & -.07 & .16 & .79 & .04 \\
\hline I sometimes her voices or things people do not see or hear & .43 & -.05 & .43 & .08 \\
\hline I feel depressed & -.01 & .02 & -.05 & .94 \\
\hline I feel anxious & .04 & -.03 & -.05 & .86 \\
\hline I feel sick most of the time & -.06 & -.002 & .16 & .80 \\
\hline
\end{tabular}

Extraction method: principal component analysis; Rotation method: oblimin with kaiser normalization. 
its" association with multiple other factors. The standardized solution is shown in Figure 1. The overall fit of this model was satisfactory based on the Comparative Fit Index $(\mathrm{CFI})=.94$, the Root Mean Square Error of Approximation (RMSEA) $=.08$, and Chi-square/df $=2.86$. In addition, all factor loadings were significant $(p<.05)$ and all, but one, were greater than .6.

In addition to this four-factor third-order model, a four-factor second-order CFA model with only the psychotic and neurotic dimensions was estimated. This model was of interest because it would be more parsimonious and involve the estimation of fewer parameters. The fit of second-order model was poor; The Likelihood Ratio Chi-Square increased from 143.05, in the third order model ( $\mathrm{df}=50$ ), to 362.02 , in the second order model $(\mathrm{df}=53)$. This change in Chi-square (218.97) with $3 \mathrm{df}$ was highly significant $(p<.001)$, indicating poor fit of the second-order model. The fit indices of the second-order model were also unacceptable; $\mathrm{CFI}=.81$, and RMSEA $=.14$. We concluded that the third-order hierarchical structure has the best fit to the data. This structure suggests four underlying factors along psychotic/neurotic dimensions and a single general distress/cumulative trauma disorder factor. Figure 1 describes this hierarchical model

Reliability: Alpha reliability coefficients for the four factorial sub-scales are: $.88, .75, .73$ and .88 . Reliability and internal consistency of the entire set of items was satisfactory, alpha .85 . Test-retest reliability was conducted using 22 participants with a 6-week inter-test interval. The test-retest correlation was .78.

Convergent and Predictive validity: CTD measure correlated with Stigma Consciousness $\left(\mathrm{R}=54^{* * *}\right)$ and with being on psychotropic medications $\left(\mathrm{R}=.28^{* *}\right)$ and with torture $\left(.16^{*}\right)$.
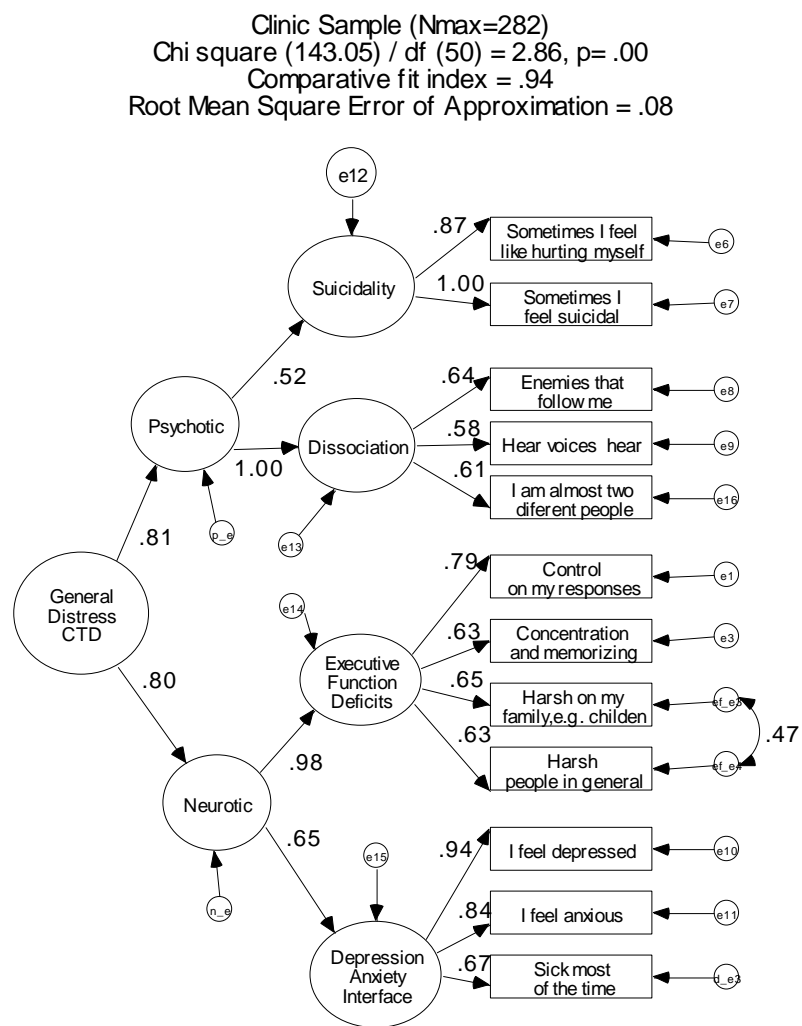

Figure 1.

Standardized solution from third order confirmatory factor analysis of cumulative trauma disorder scale.
Table 2 describes the correlation between the CTD scale, its four sub-scales and these variables.

\section{The Second Study}

The purposes of the second study were a) to examine the psychometric and predictive validity of the 12 item CTD scale in a community sample of Iraqi immigrants, and b) to examine the potential of addition items to improve scale validity. Multigroup CFA with structured means and Multiple regressions were used for the analyses. With regard to predictive validity we expected that cumulative trauma exposure (CT exposure scale) would predict CTD, PTSD and physical health.

\section{Procedures and Participants}

The current study sample was drawn based on an estimation study of Michigan's Iraqi refugee population, as of mid-2001, of gender and age groups, and was conducted by Jay Weinstien and Elvira del Pozo (2001) especially for the purpose of the study. It is estimated that about 33,000 Iraqi refugees were living in Detroit's metropolitan area at the time of the study. A quota sample of 501 that represented Iraqi community in Wayne County, Michigan was designed. Informed consents were obtained from adult participants; for adolescents, parental consents and adolescent assents were obtained. No identifying information was recorded that could link the participants to the data; the disclosure of the data could not reasonably place the participants at any risk for any liability. Interviews were conducted face-to-face in Arabic by Iraqi paraprofessionals who recruited participants who fit the quota requirements. The data was collected from December 2002 to March 2003. An experienced Iraqi community liaison and the research team coordinated the recruitment of subjects, using snowballing techniques, and contributed to data management to assure the representation provided by the estimation study.

The sample included 276 males (54.9\%) and 225 females (45.1\%), with ages ranging between 12 and 79 (mean age 35.7; SD. of 13.95). The age groups matched the estimation study, with $9.4 \%$ ages $12-19 ; 32.1 \%$ ages $20-29 ; 25.9 \%$ ages 30 $39 ; 15 \%$ ages $40-49 ; 11.2 \%$ ages $50-59 ; 4.6 \%$ ages $60-69$; and $1.8 \%$ ages 70 and up. The sample's marital statuses included $60 \%$ married, $31 \%$ single, $4 \%$ separated, and $4 \%$ divorced. Regarding education, $5.4 \%$ were illiterate, $56 \%$ had education that ended in the range from second grade to high school, and $34 \%$ were college students or graduates. Ten percent had resided in the US for two years or less, $32 \%$ for $3-5$ years, $36 \%$ for $6-10$ years and $21 \%$ had lived here for more than 10 years. In terms of religion, $90 \%$ were Shiite Muslims, $5.8 \%$ were Sunni Muslims, and 3.2\% were Christians. Regarding annual gross income, $15.1 \%$ made less than $\$ 5000 ; 23.4 \%$ earned between $\$ 5000$ and $\$ 10,000 ; 19.3 \%$ earned between $\$ 10,000$ and $\$ 15,000 ; 17.2 \%$ earned between $\$ 15,000$ and $\$ 20,000 ; 9.1 \%$ earned between $\$ 20,000$ and $\$ 25,000 ; 6.2 \%$ earned between $\$ 25,000$ and $\$ 30,000 ; 3 \%$ earned between $\$ 30,000$ and $\$ 35,000$; and $6.8 \%$ made over $\$ 35,000$.

\section{Measures}

Cumulative Trauma Events Measure CT (22 items): The measure was based on the DTBF framework and contains 22 kinds of traumatic experiences, for example torture, war, rape, sexual and physical abuse, car accidents, abandonment by 
Table 2.

Pearson correlations between CTD scales and its subscales with different mental health indicators.

\begin{tabular}{lccc}
\hline & On psychotropic medications & Stigma consciousness scale & Tortured \\
\hline Cumulative trauma disorder scale & $.28^{* *}$ & $.54^{* *}$ & $16^{*}$ \\
Executive functions deficits sub-scale & $.27^{* *}$ & $.58^{* *}$ & .10 \\
Suicidality sub-scale & .12 & $.19^{* *}$ & .09 \\
Psychosis/dissociation sub-scale & $.22^{* *}$ & $.35^{* *}$ & $.16^{*}$ \\
Depression/anxiety comorbidity sub-scale & $.23^{* *}$ & $.55^{* *}$ & .09 \\
\hline
\end{tabular}

Note: ${ }^{*} p<.05 ;{ }^{* *} p<.01 ;{ }^{* * *} p<.001$ (Two-tailed).

parents, discrimination, and natural disasters. Each participant was asked to mention the frequency of each kind of trauma that happened to him/her. The measure was a short form of a more elaborate measure and was based on the taxonomy of trauma developed by Kira (2001). Alpha reliability coefficient was .846 . Factor analysis found six factors: collective identity trauma, for example "discriminated against or threatened due to race or ethnicity or religion", family trauma, for example divorce and family history of violence, secondary traumatization or interdependence trauma, personal identity/ autonomy trauma, for example sexual abuse, survival trauma, and abandonment trauma (Kira et al., 2008). Six sub-scales were developed based on these results. The CT scale was found to have good predicttive validity as it correlated significantly with PTSD and CTD (cumulative trauma disorders) scales (see Kira et al., 2008).

PTSD Measure (CAPS-2): widely used to assess PTSD. It is a structured, clinical interview used to assess 17 symptoms. CAPS demonstrated high reliability ranging from $.92-.99$ and good convergent and discriminant validity (Weathers et al., 2001). Betemps et al., 2003, found that the frequency subscale produced measures that encompass the level of severity as well. In this study, we used the frequency sub-scale of CAPS-2 that is currently widely used in psychiatric literature. It showed in our study high internal consistency reliability with Alpha of .973.

Health Scale (12 items): The measure was developed by Kira et al. in previous study on Iraqi refugees (Kira et al, 2006). It is based on ICD-9-CM codes for selected general medical conditions adopted and published in DSM IV. It includes questions about self-reported health and the kinds of health problem the participant has, for example neurological, circulatory, digestive system, urinary system, musculoskeletal, endocrine, other life threatening and other non-life threatening illnesses. It has Alpha reliability in this study of .751. Principal component Factor analysis found three factors: specific health problems, life threatening illness, and other non-life threatening illness.

Posttraumatic growth attitude measure (1 item). We used the item "Every trauma that does not kill me makes me stronger" as a single-item measure to predict posttraumatic growth attitude. In the previous study, this one-item measure was found to have good predictive validity. We used Wanous and Hudy's (2001) method of estimating single-item reliability. Using futuristic orientation as a correlate and correction of attenuation formula and factor analysis, the measure's reliability ranged between .78 (conservative estimate) and .89 (liberal estimate).

Cumulative Trauma Disorders measure CTD (10 items) (developed from the previous study). We omitted the two items with correlated residuals leaving a scale with 10 items. How- ever we added another five items to improve its validity. Table 2 shows the common item correlations, means and SD in the two studies (clinic and community studies).

\section{Psychometric Validity-10 Item Version}

The item means and inter-item correlations for each group are shown Figure 2. It is readily apparent that the clinic group scored higher on each item and that the correlations among items were higher in the community group. It is also apparent that community participants were not frequently endorsing any of the CTD items because the item mean scores were near 1 . Thus differences between groups in item means could be due to many respondents choosing a category just higher than the minimum or to a few respondents using the more extreme ends of the scale. To address the question, what proportions of the cases are giving responses greater than one, the items were dichotomized (one vs. greater than one). The results are shown in Figure 2. The two items from the suicide factor were the least frequently endorsed in either group, .18 and .19 for "kill self" and "hurt self", respectively, in the community group; and .40 and .41 , respectively in the clinic group. These items are endorsed about twice as often in the clinic sample than the community sample (e.g., . $40 / .18=2.27$ ). The most frequently endorsed items were from the neuroses dimension. In fact, the rank ordering here was perfect and is consistent with expectations. All the neuroses items were endorsed more frequently than psychoses items in both groups. Two of the most frequently endorsed items were also the psychoses dimension. Note that many of the items in the clinical group were endorsed (i.e., a response greater than 1) by $80 \%$ or more of the participants.

More interesting is consideration of what items show the greatest difference. It is naive however to think of large differences in proportion of endorsement as indicating higher item discrimination, as we will demonstrate later. In any event, two items from the Psychoses-Disassociation factor were three or four times more likely to be endorsed in the clinic group (see, "feel different" and "hear voices"). These observations on group differences are interesting but they raise questions about the psychometric characteristics of the CTD that need to be addressed with more sophisticated methods. Does the instrument measure the same factors in the clinical and community group in spite of such obvious differences in item means and in the magnitude of the inter-item correlations? Are the same psychological constructs being measured in the same way in the clinically referred and the community sample participants or the differences are expected and indicative of the discriminative 


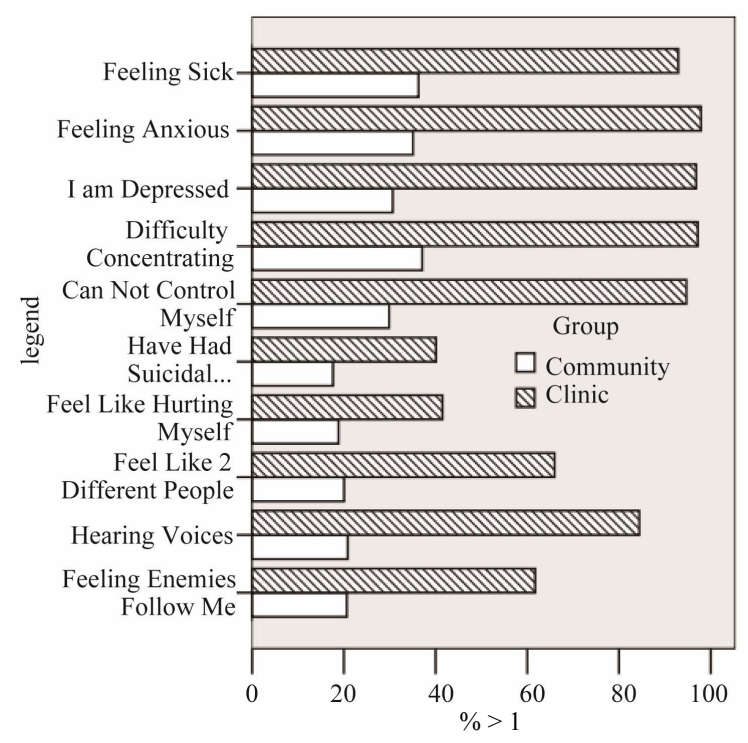

Figure 2.

Percent of cases in each group endorsing each item with response option higher than one. All differences were significant $(p<.01)$.

validity of the scale? Patients in mental health clinic are expected to score much higher on CTD than community members.

\section{Measurement Invariance of the CTD-10}

Multigroup structural equation modeling with structured means is being increasing used to compare factor structures across naturally defined or clinically important groups (e.g., Muthén, 1989). This analysis incorporates latent factor means and observed item means so that the groups with lower mean scores on the factors are also expected to have lower mean scores on the items. Items with means that are higher or lower than expected given the expected score on the factor can be identified as biased and taken into account in the analysis or removed from the scale before between-group comparisons are made. The first and lowest level of invariance is configural invariance. This address the question, are the same factors present in both groups.

Configural invariance. We performed a MG-SEM to test configural invariance. The four-factor structure of the CTD scale identified in study 1 was used for the baseline models for comparing the psychometric equivalence of the instrument across clinic and community groups. The same baseline model was estimated in each group. The overall fit of this baseline model was marginally acceptable $\left[\mathrm{X}^{2}(58, \mathrm{~N}=781)=358.83, p\right.$ $<.01, \mathrm{CFI}=.94$; and RMSEA $=.08]$ indicating that the fourfactor structure was appropriate (see Table 3). Modification indexes were examined for sources of misfit. Modification indices are measures of the improvement in fit that results from freeing a model parameter that is constrained. Each constrained parameter is thus associated with a modification index. Several options were present in the community group model. Allowing "I am depressed" and "Can't control myself" to load on the Suicide factor would have resulted in a substantial improvement in fit $\left[X^{2}(56, N=781)=265.90, p<.01, C F I=.96\right.$; and RMSEA $=.07]$. These additions made theoretical sense as well. However, the standardized path coefficients of these cross- loaded paths were much smaller in magnitude than other path coefficients in the model (.30 and .24, for "Can't control myself", and "I am depressed", respectively). For this reason fit was improved by allowing residual errors to be correlated across two items - "Feel like hurting myself", and "Can't control myself". The model is shown in Figure 1. The fit of this baseline model with 1 correlated residual in the community group was still only marginal $\left[\mathrm{X}^{2}(57, \mathrm{~N}=781)=317.17, p\right.$ $<.01, \mathrm{CFI}=.95$; and RMSEA $=.08]$. Moreover, note the extremely high correlations among the two neurotic factors on the one hand, and the two psychoses factors on the other. In effect, this is a two-factor solution.

Noting the hierarchical structure of the CTD scale identified in Study 1 and the present results, the question that arises is this, would a two-factor latent structure be more invariant across groups that vary in base rate symptomatology? We addressed this question by fitting a MG-CFA to the two-factor structure as found in Study 1. This model fit more poorly than the 4-factor model. The increase in Chi-square was highly significant and the fit indexes were unacceptable (see Table 4). Finally, a one factor model was simultaneously fit to both groups. The model had fit significantly worse than the two-factor or four-factor model. We conclude that the four-factor solution is invariant but undifferentiated in the community sample.

Weak factor invariance. Having established an acceptable baseline model, the next step used to assess measurement invariance was the test the equivalence of factor loadings across groups, referred to as weak factorial invariance (Meredith, 1993). As a result of fitting the multi-group SEM with loadings constrained to be equal across groups the Chi-Square increased by 50.79 units. With a change in degrees of freedom of 7 , this was highly significant indicating that constraining the loadings to be equal across groups substantially reduced the fit of the model. The modification index of each constrained loading was examined to identify the sources of misfit. Only one was larger than 4 , the minimum expected change in Chi-square. The constraint on the item loading for "I can not control myself" was removed and the model was re-estimated. Removing this constraint significantly improved Chi-square but had no effect on the fit indices (see Table 3). The loading (un-standardized) for this item in the clinic group was 1.35 ; in the community group it was .67. No other loading coefficients were this discrepant. This discrepancy indicates that the item, "I can not control myself", was not as discriminating in the community sample as in the clinic sample. Because this item is functioning different across the groups, when factor means are compared across groups this item should be weighted differently for each group. Allowing only the loading of one or a small number of items to vary while holding others constant is as partial invariance (Byrne, Shavelson, \& Muthén, 1989).

This partial invariance model was still significantly different from the baseline model, $\left(X^{2}(5, N=501)=24.83\right.$ (critical value $=11.07, p<.01)$. so there would be some justification for accepting partial invariance. However, because of the large sample size and the well known sensitivity of Chi-Square to large sample sizes, we looked at the change in descriptive fit indices to further guide model selection. The CFI was reduced by only .003 and the RMSEA by less than .01 . Using the criteria of Cheung and Rensvold, (2002) a change in CFI equal to or smaller than .01 indicates that the hypothesis of invariance should not be rejected. With factor loading invariance established, the next step was to constrain the item intercepts to be 
Table 3.

CTD item correlations, means, and standard deviations for community $(\mathrm{N}=499)$ and clinic $(\mathrm{N}=282)$ sample — community above and clinic below.

\begin{tabular}{|c|c|c|c|c|c|c|c|c|c|c|c|}
\hline & & 1 & 2 & 3 & 4 & 5 & 6 & 7 & 8 & 9 & 10 \\
\hline Factor & Item & & & & & & & & & & \\
\hline P-Dis & 1. enemfoll & & .72 & .77 & .72 & .60 & .50 & .42 & .56 & .43 & .43 \\
\hline P-Dis & 2. hearvoi & .32 & & .72 & .71 & .69 & .45 & .45 & .58 & .36 & .43 \\
\hline P-Dis & 3. feeldiff & .50 & .32 & & .71 & .61 & .52 & .41 & .53 & .40 & .44 \\
\hline P-Suic & 4. hurtself & .32 & .21 & .27 & & .74 & .54 & .35 & .45 & .34 & .35 \\
\hline P-Suic & 5. selfkill & .35 & .28 & .29 & .87 & & .43 & .42 & .53 & .35 & .34 \\
\hline N-ExF & 6. cantcont & .27 & .37 & .30 & .26 & .28 & & .62 & .53 & .62 & .62 \\
\hline N-ExF & 7. diffconc & .18 & .42 & .13 & .13 & .20 & .53 & & .70 & .76 & .79 \\
\hline N-AxD & 8. deparat & .20 & .31 & .16 & .19 & .17 & .42 & .37 & & .69 & .67 \\
\hline $\mathrm{N}-\mathrm{AxD}$ & 9. anxious & .15 & .38 & .18 & .17 & .15 & .40 & .38 & .79 & & .71 \\
\hline \multirow[t]{5}{*}{ N-AxD } & 10. feelsick & .30 & .38 & .24 & .20 & .22 & .35 & .28 & .63 & .53 & \\
\hline & Com. Mean & 1.34 & 1.36 & 1.32 & 1.28 & 1.29 & 1.58 & 1.82 & 1.67 & 1.79 & 1.81 \\
\hline & Com SD & 0.76 & 0.83 & 0.75 & 0.68 & 0.76 & 1.03 & 1.24 & 1.16 & 1.22 & 1.22 \\
\hline & Clin Mean & 2.91 & 3.98 & 2.84 & 2.36 & 2.33 & 4.44 & 4.64 & 4.75 & 4.79 & 4.43 \\
\hline & Clin SD & 1.74 & 1.46 & 1.61 & 1.71 & 1.72 & 1.02 & 0.89 & 0.86 & 0.77 & 1.21 \\
\hline
\end{tabular}

equal across groups.

Strong invariance. Differences in between group intercepts represented differences in item difficulty over and above what could be accounted for by differences in latent means. As a result of constraining the intercepts the change in Chi-Square was significant, indicating a significant decrease in the model fit, $p<.05$. The CFI also dropped by an appreciable amount. In order to examine the source of the misfit, modification indices were again examined. One intercept term was identified; "Hearing voices" from the Dissociation Factor. This term was freed and the model was estimated again. The fit of the resulting model (partial strong invariance) was acceptable. The results are displayed in Table 3.

\section{Part II}

We examined the increase in reliability and predictive validity by adding more items to the previous version (substance abuse, and feeling apathetic with no emotions, difficulty functioning, and sleep problems).

\section{Psychometric Validity-15 Item Revised Measure}

Coefficient alpha reliability was .947 . Exploratory factor analysis with Varimax rotation yielded two factors accounted for $74.93 \%$ of the variance. The first factor is a neurotic factor that is highly loaded on executive function deficits, depression, anxiety and emotional deficits items; the second factor is more of psychotic factor that is highly loaded on suicidality, hearing voices, and dissociation items. Depression and self-control are significantly loaded in both factors. This analysis suggests that the additional items might be important additions because they each loaded high on one of the factors-particularly the neurotic factor. Table 4 represents this two factor solution.

\section{Predictive Validity-15 Item Revised Scale}

CTD significantly correlated with PTSD and poor health. This demonstrates the convergent validity of the scale. It correlated significantly with cumulative trauma scale (cumulative trauma dose) which demonstrates the predictive validity of the scale. It correlated negatively with Post-traumatic growth which demonstrates the divergent validity of the scale. These suggest adequate discriminative and predictive validity. Table 5 presents these correlations.

Further, we predicted that CTD would affect health above and beyond the effects of different kinds of traumas [as measured by the cumulative trauma events scale and subscales]. Multiple regression analysis with Health scale as dependent variable and CTD, and the CT subscales (collective identity traumas, personal identity traumas, family traumas, interdependence traumas (secondary traumatization), and survival traumas as independent variables) as predictors was performed. CTD was a significant predictor of poor health above and beyond the effects of different types of traumas. Table 6 summarizes these findings.

To test the effects of CTD on different health conditions Multivariate analysis of variance with CTD as the independent variable and different health conditions as dependent variables. CTD contributed significant variance to neurological, circulatory, respiratory, digestive, and musculoskeletal and other lifethreatening and non-life-threatening illness. CTD accounted for .346 of the variance in neurological problems. Neurological system seems to be the most affected body system by CTD. Table 7 presents these effects. 


\section{A. KIRA ET AL.}

Table 4.

Assessment of measurement invariance.

\begin{tabular}{ccccccccccc}
\hline Model & $\begin{array}{c}\text { Type of Latent Structure } \\
\text { Invariance }\end{array}$ & Chi-Square & df & $p$ & $\begin{array}{c}\text { Chi-Square } \\
\text { Change }\end{array}$ & df & $p$ & CF1 & RMSEA \\
\hline 1 & 4-Factor-Configural & 317.17 & 57 & $<.01$ & & & & .949 & .08 \\
2 & 2-Factor Configural & 603.30 & 68 & $<.01$ & 286.13 & 11 & $<.01$ & .904 & .10 \\
3 & 1-Factor Configural & 1836.42 & 70 & $<.01$ & 1519.25 & 2 & $<.01$ & .661 & .18 \\
4 & 4-F-Weak & 367.96 & 63 & $<.01$ & 50.79 & 7 & $<.01$ & .941 & .08 \\
5 & 4-F-Partial Weak & 342.00 & 62 & $<.01$ & 25.96 & 1 & $<.01$ & .946 & .08 \\
6 & 4-F-Strong & 438.59 & 67 & $<.01$ & 96.59 & 5 & $<.01$ & .928 & .08 \\
7 & 4-F-Partial Strong & 372.09 & 66 & $<.01$ & 66.5 & 1 & $<.01$ & .940 & .08 \\
\hline
\end{tabular}

Table 5.

Factor loadings for the two factors solution of CTD scale in the community study (N=501).

\begin{tabular}{lcc}
\hline \multirow{2}{*}{ Items } & \multicolumn{2}{c}{ Component } \\
\cline { 2 - 3 } & 1 & 2 \\
\hline No Emotion & .91 & .12 \\
Difficulty Functioning in One or More Areas & .90 & .19 \\
Difficulty Concentrating & .89 & .24 \\
Feeling Sick & .86 & .23 \\
Difficulty Sleeping & .85 & .27 \\
Feeling Anxious & .84 & .22 \\
I am Depressed & .69 & .48 \\
Can Not Control Myself & .64 & .41 \\
Feel Like Hurting Myself & .16 & .87 \\
Abuse Drugs & .15 & .86 \\
Have Had Suicidal Thoughts & .20 & .84 \\
Hearing Voices & .23 & .83 \\
Feeling Enemies Follow Me & .29 & .79 \\
Feel Like 2 Different People & .27 & .79 \\
I Try to Avoid People & .45 & .69 \\
\hline
\end{tabular}

Extraction method: principal component analysis; Rotation method: varimax with kaiser normalization.

Table 6.

Pearson correlations between CTD and other scales.

\begin{tabular}{ccccc}
\hline Variables & $\begin{array}{c}\text { Poor Health } \\
\text { scale }\end{array}$ & $\begin{array}{c}\text { Post-trauma } \\
\text { growth attitude scale }\end{array}$ & $\begin{array}{c}\text { Cumulative } \\
\text { Trauma Scale }\end{array}$ & PTSD Scale \\
\hline $\begin{array}{c}\text { Cumulative Trau- } \\
\text { ma Disorder Scale } \\
\text { CTD) }\end{array}$ & $.28\left(^{* * *}\right)$ & $-.25\left(^{* * *}\right)$ & $.27\left(^{* * *}\right)$ & $.59\left(^{* * *}\right)$ \\
\hline
\end{tabular}

Note: ${ }^{*} p<.05 ;{ }^{* *} p<.01 ;{ }^{* * *} p<.001$ (two-tailed).

Table 7.

Multiple regressions for the effects of CTD on health after controlling for the effects of different trauma types.

\begin{tabular}{lccccc}
\hline & \multicolumn{2}{c}{$\begin{array}{c}\text { Unstandardized } \\
\text { Coefficients }\end{array}$} & & \multicolumn{1}{c}{$\mathrm{t}$} \\
\cline { 2 - 3 } & B & Std. Error & Beta & \\
\hline Collective Identity Trauma (e.g., Discrimination) & .32 & .10 & .14 & $3.30^{* * *}$ \\
Family Trauma & .43 & .09 & .19 & $4.64^{* * *}$ \\
interdependence (Secondary) Trauma & .43 & .09 & .19 & $4.64^{* * *}$ \\
Personal Identity Trauma (e.g., Sexual Abuse) & .01 & .09 & .004 & .10 \\
Survival Trauma (Natural and Man-Made) & .32 & .09 & .14 & $3.47^{* * *}$ \\
Attachment/Abandonment Trauma & -.02 & .09 & -.01 & -.19 \\
Cumulative Trauma Disorder Scale & .04 & .01 & .22 & $4.99^{* * *}$ \\
\hline
\end{tabular}

Note: dependent variable: health scale; Note: ${ }^{*} p<.05 ;{ }^{* *} p<.01 ;{ }^{* * *} p<.001$ (two-tailed). 
Table 8.

Tests of between-subjects effects of CTD on health disorders.

\begin{tabular}{|c|c|c|c|c|c|c|}
\hline Source & Dependent Variable & $\mathrm{df}$ & Mean Square & F & Partial Eta Squared & Observed Power \\
\hline \multirow[t]{10}{*}{ CTD } & Neurological Problems & 44 & .15 & $5.12^{* * *}$ & .346 & 1.000 \\
\hline & Blood Disease & 44 & .02 & 1.01 & .094 & .952 \\
\hline & Circulatory Problem & 44 & .10 & $1.94^{* *}$ & .167 & 1.000 \\
\hline & Respiratory Problem & 44 & .11 & $2.05^{* * *}$ & .175 & 1.000 \\
\hline & Digestive Problems & 44 & .21 & $2.47^{* * *}$ & .203 & 1.000 \\
\hline & Urinary Problems & 44 & .12 & .89 & .084 & .913 \\
\hline & Musculoskeletal Problems & 44 & .22 & $1.55^{* *}$ & .138 & .998 \\
\hline & Endocrine Problem & 44 & .07 & .93 & .088 & .930 \\
\hline & Other Life Threat. Illness & 44 & .01 & $1.41^{*}$ & .127 & .995 \\
\hline & Other non-Life Threat Illness & 44 & .07 & $2.81^{* * *}$ & .225 & 1.000 \\
\hline
\end{tabular}

Note: ${ }^{*} p<.05 ;{ }^{* *} p<.01 ;{ }^{* * *} p<.001$ (two-tailed).

Table 9.

Subsequent studies utilized CTD scale.

\begin{tabular}{|c|c|c|c|}
\hline Source & Sample and Subject Characteristics & Alpha & Predictive Validity \\
\hline $\begin{array}{l}\text { Kira, Lewandowski, } \\
\text { Somers, Yoon, \& } \\
\text { Chiodo (2012b) }\end{array}$ & $\begin{array}{l}\text { Community Sample adolescents: Total participants were } 390 \\
\text { students from grades } 5-12 \text {, age ranged between } 11-18 \text {, } \\
\text { (mean }=13.56, \mathrm{SD}=1.49 \text { ) with } 45.6 \% \text { age group from } 11- \\
13 \text {, and } 54.6 \% \text { age group } 14-18 . \text { It included } 52 \% \text { Iraqi } \\
\text { refugee adolescents, and } 47 \% \text { African American } \\
\text { adolescents, } 46.4 \% \text { males and } 53.6 \% \text { females. }\end{array}$ & It has alpha of .91 & $\begin{array}{l}\text { Cumulative Trauma (CT) predicted CTD. } \\
\text { Psychotic sub-scale predicted higher discrep- } \\
\text { ancy between verbal and perceptual IQ, CTD } \\
\text { is highly correlated with PTSD, cumulative } \\
\text { trauma, and Adolescents' psychopathology. }\end{array}$ \\
\hline
\end{tabular}

Clinic sample included 399 adult clients, 82.7\% from Arabic and $17.3 \%$ from non-Arabic origins. Age ranged from 18 76 , with mean of 39.66 and SD of 11.45 . Those from non-Arabic origins included Americans as well as refugees and Asylum seekers from different countries. It included $53.5 \%$ males and $46.5 \%$ females, $14.2 \%$ illiterate, $4.7 \%$ college graduates, $27.4 \%$ elementary school, $38 \%$ middle to junior high, and $15.5 \%$ high school graduates. Eighty two percent of the participants were making less than $15.000 \$$ a year.

Community sample adolescents from Gaza: Participants included 442 adolescents, $47.5 \%$ males and $52.5 \%$ females. Participants included 5\% from villages' residents, 50.3\%

Kira et al. (2011a) from Gaza city residents, and $44.7 \%$ from refugee camps' residents. Age ranged between 11 and 19, with mean of 15.89 and SD of 2.86. Family size average was 9.77 and SD of 2.79 .

Community sample adult: Participants were 132 adult from Gaza, age range between 18 and $63(\mathrm{M}=31.21, \mathrm{SD}=9.77)$, Alpha $=.90$ $58 \%$ were males and $42 \%$ females. Family size mean was 7.24 with SD of 3.22

Community sample adolescents from West Bank: Participants were 438 adolescents, high school students from West Bank in Palestine. They included $54.6 \%$ males, and $45.4 \%$

Kira et al. (2011b) females. Age ranged from $12-19$, mean age was 15.66 , $\mathrm{SD}$ of 1.43 . Family size ranged from $2-22$ with mean of 7.99 , SD $2.69 .40 \%$ of the participants were from middle school and $60 \%$ from high school.

Alpha $=.95$

Alpha $=.97$

Alpha for total $=.98$, Bhutanese $=.92$ Burmese $=.95$ Iraqi $=93$ Somali $=.92$ and \& Templin, (2010), and Clinic sample of Refugee Torture Survivors and Kira, Ashby, Lewandowski, their families $\mathrm{N}=359$ from 31 countries Smith, \& Odenat, (2012)
CT predicted CTD. CTD was found to be highly correlated with PTSD, anxiety, depression, and annihilation anxiety measures which indicate a good convergent validity. It was found to be highly negatively correlated with futuristic orientation, socio-cultural adjustment and post-traumatic growth which indicate adequate divergent validity.

CT predicted CTD. CTD was highly correlated with negative appraisal of CT, PTSD, anxiety, depression, and annihilation anxiety and negatively correlated with positive appraisal of CT, stress related growth and futuristic orientation

CTD had high negative correlation with stress related growth $\left(-.337^{* * *}\right)$. CT predicted CTD.

CT predicted CTD. CTD was highly correlated with negative appraisal of CT, PTSD, anxiety, depression, and annihilation anxiety and negatively correlated with positive appraisal of $\mathrm{CT}$, stress related growth and futuristic orientation

CT highly predicted CTD. CTD was highly associated with PTSD. Gender discrimination predicted CTD.

all others $=.87$ 


\section{Summary and Discussion}

Advances in trauma theory open the door to new perspectives in assessing and identifying post-cumulative trauma profiles. Etiological analysis assumes that different types of trauma profiles may yield different patterns of symptoms. CTD are defined on clinical and empirical basis and are based on the analysis of cause and effect. This paper introduced a new approach for identifying and measuring symptom profiles that follows a certain trauma profile instead of looking to a single diagnosis. Cumulative trauma disorders profiles can include sub-models according to the different trauma profiles and their accumulative effects that produce different symptom profiles. Iraqi refugees' traumatic experiences provide us with a typical and unique example of specific cumulative trauma experience and resulted syndromes profile. The paper proposed the model of cumulative trauma disorder in refugees. The model was derived from the literature and from clinical experience. Using an operational definition of CTD, a 15 items scale to measure CTD was developed. The new scale has adequate reliability, construct, concurrent and discriminative validity that are replicated across two studies. It has high alpha reliability (ranged from .850 and .949). Exploratory and confirmatory factor analysis provided evidence of content and construct validity as it found a parsimonious hierarchical structure that include the four dimensions of CTD that were identified in its operational definition. This provides support for the conceptual accuracy of the scale. Factor analysis provided support for the structural validity of the scale as the extracted factors in the first study accounted for $71.65 \%$ of the variance and the resulted model fits nicely. In the second study extracted factors accounted for $74.9 \%$ of the variance. The structural validity coefficients of .72 and .75 are considered adequate. Advanced SEM analysis found evidence of partial strong invariance of the scale between the clinic and the community samples. Using multiple regression, correlation analysis and ANOVA, we found significant association between CTD and poor health. It correlated significantly with neurological, respiratory, circulatory, musculoskeletal and digestive health problems. This supports the criterion and predictive concurrent validity of the measure and the CTD model in refugees. Moreover, CTD provided an explanatory power of poor health over and above the cumulative trauma dose and types. This provides support for the incremental validity of the scale. High correlation between CTD and PTSD scale support the convergent validity of CTD. The positive correlation of CTD with Cumulative trauma, backlash trauma, stigma consciousness, and torture provides evidence for its nomological and predictive validity, as it fits the theoretical prediction of CTD as a result of Refugees' cumulative trauma. Further, the clinic group as expected scored significantly higher on each item of the scale than in the community sample. The measure seems to be more differentiated and discriminating in the clinic sample.

More models of CTD that fit different cumulative trauma patterns need to be developed and tested on different populations as well. The goal is to establish cause-effect or etiological analyses for the different cumulative traumas profiles and different patterns of symptoms.

CTD measure is a good parsimonious measure that is based on good theory, valid empirical evidence and can be utilized to screen for mental health in public health setting and especially in clinics that screen, minorities, refugees, prison inmates and mental health patients, adults and adolescents. Utilizing the measure to screen refugees for mental health prompted to add an extra item to screen for suicidal plans and attempts (item 16). The measure can be used to evaluate psychiatric vital signs in multiply traumatized populations.

Subsequent studies, on different cultures, on community and clinical populations of adults and adolescents, found that CTD has good reliability and predictive validity. Tables 8 and 9 summarize some of the subsequent studies that utilized CTD scale.

\section{REFERENCES}

Arfken, C. L., Kubiak, S. P., \& Farrag, M. (2009). Acculturation and polysubstance abuse in Arab-American treatment clients. Transcultural Psychiatry, 46, 608-622. doi: $10.1177 / 1363461509351364$

Betemps, E., Smith, R., Baker, D., \& Rounds-Kugler, B. (2003). The measurement precision of the Clinician Administered PTSD sale: A RASCH model analysis. Journal of Applied Measurement, 4, 59-69.

Bowlby, J. (1988). A secure base: Parent child attachment and healthy human development. New York: Basic Books.

Breslau, N., Chilcoat, H., Kessler, R., \& Davis, G. (1999). Previous exposure to trauma and PTSD effects of subsequent trauma: Results from the Detroit area survey of trauma. American Journal of Psychiatry, 156, 902-907.

Byrne, B. M., Shavelson, R. J., \& Muthén, B. (1989). Testing for the equivalence of factor covariance and mean structures: The issue of partial measurement invariance. Psychological Bulletin, 105, 456466. doi:10.1037/0033-2909.105.3.456

Cassidy, J., \& Shaver, P. (1999). Handbook of attachment: Theory, research, and clinical applications. New York: Guilford Press.

Cassiman, S. A. (2005). Toward more inclusive poverty knowledge: Traumatological contributions to the poverty discourse. Cutting Edge of Social Policy Research, 4, 93-106.

Cattell, R. B. (1966). The scree test for the number of factors. Multivariate Behavioral Research, 1, 629-637. doi: $10.1207 / \mathrm{s} 15327906 \mathrm{mbr} 0102 \quad 10$

Cheung, G. W., \& Rensvold, R. B. (2002). Evaluating goodness-of-fit indexes for testing measurement invariance. Structural Equation Modeling, 9, 233-255. doi:10.1207/S15328007SEM0902_5

Chochinov, H., Wilson, K., Ennus, M., \& Lander, S. (1997). "Are you depressed" screening for depression in the terminally ill. American Journal of Psychiatry, 145, 674-676.

Cloitre, M., Stolbach, B., Herman. J., van der Kolk, B., Pynoos, R., Wang, J., \& Petkova, E. (2009). A developmental approach to complex PTSD: Childhood and adult cumulative trauma as predictors of symptom complexity. Journal of Traumatic Stress, 22, 399-408.

Cook A., Blaustein, M., Spinazzola, J., \& van der Kolk, B. (2003). Complex trauma in children and adolescents: White paper. Allston, MA: National Child Traumatic Stress Network, Complex Trauma (NCTSN) Task force.

Fao, E. B. (1996). Failure of emotional processing: Post-trauma psychopathology and its treatment. Invited Address Presented in the American Psychological Annual Convention, Toronto.

Ford, J. (1999). Disorders of extreme stress following war-zone military trauma: Associated features of posttraumatic stress disorder or comorbid but distinct syndromes? Journal of Consulting \& Clinical Psychology, 67, 3-12. doi:10.1037/0022-006X.67.1.3

Freyd, J. J., DePrince, A. P., \& Gleaves, D. (2007). The State of Betrayal trauma theory: Reply to McNally (2007)-Conceptual issues and future directions. Memory, 15, 295-311.

doi:10.1080/09658210701256514

Hamby, S., Finkelhor, D., Turner, H., \& Ormrod, R. (2010). The overlap of witnessing partner violence and child maltreatment and other victimizations in a nationally representative survey of youth. Child Abuse \& Neglect, 34, 734-741. doi:10.1016/j.chiabu.2010.03.001

Herman, J. L. (1992). Trauma and recovery. New York: Basic Books. 
Holmes, D., \& Tinnin, L. (1995). The problem of auditory hallucinations in combat PTSD. Traumatology: An International Journal, 1, 1-7.

Kaiser, H. F. (1960). The application of electronic computers to factor analysis. Educational and Psychological Measurement, 20, 141-151. doi:10.1177/001316446002000116

Kaysan, D., Rosen, G., Bowman, M., \& Resick, P. (2010). Duration of exposure and dose-response model of PTSD. Journal of Interpersonal Violence, 25, 63-74. doi:10.1177/0886260508329131

Kira, I. (1999). Type III trauma and Iraqi refugees' traumatic experiences. Paper presented in the American Psychological Association Annual Convention, Boston.

Kira, I. (2001). Taxonomy of trauma and trauma assessment. Traumatology, 2, 1-14.

Kira, I. (2002). Torture assessment and treatment: The wraparound approach. Traumatology: An International Journal, 8, 23-51.

Kira, I. (2004). Secondary trauma in treating refugee survivors of torture, and their families. Torture, 14, 38-44.

Kira, I. (2010). Etiology and treatments of post-cumulative traumatic stress disorders in different cultures. Traumatology: An International Journal, 16, 128-141.

Kira, I., Lewandowsk, L., Templin, T., Ramaswamy, V., Ozkan, B., \& Mohanesh, J. (2008). Measuring cumulative trauma dose, types and profiles using a development-based taxonomy of trauma, Traumatology, 14, 62-87. doi:10.1177/1534765608319324

Kira, I., Smith, I., Lewandowski, L., \& Templin, T. (2010a).The effects of perceived gender discrimination on refugee torture survivors: A cross-cultural traumatology perspective. Journal of the American Psychiatric Nurses Association, 16, 299-306. doi:10.1177/1078390310384401

Kira, I., Lewandowsi, L., Templin, T., Ramaswamy, V., Ozkan, B., \& Mohanesh, J. (2010b). The effects of perceived discrimination and backlash on Iraqi refugees' physical and mental health. Journal of Muslim Mental Health, 5, 59-81. doi:10.1080/15564901003622110

Kira, I., Templin, T., Lewandowski, L., Ramaswamy, V., Bulent, O., Abu-Mediane, S., Mohanesh, J., \& Alamia, H. (2011a). Cumulative tertiary appraisal of traumatic events across cultures: Two studies. Journal of Loss and Trauma: International Perspectives on Stress \& Coping, 16, 43-66.

Kira, I., Alawneh, A. N., Aboumediane, S., Mohanesh, J., Ozkan, B., \& Alamia, H. (2011b). Identity salience and its dynamics in palestinians adolescents. Psychology, 2, 781-791. doi: $10.4236 /$ psych. 2011.28120

Kira, I., Ashby, J., Lewandowski, L.; Smith, I., \& Odenat, L. (2012a). Gender inequality and its effects in females torture survivors. Psychology, 3, 352-363. doi:10.4236/psych.2012.34050

Kira, I., Lewandowski, L., Somers, C., Yoo, J., \& Chiodo, L. (2012b). The linear and non-linear associations between multiple types of trauma and IQ discrepancy indexes in African American and Iraqi refugee adolescents. Journal of Child \& Adolescent Trauma, 5, 47-62.

Kira, I., Abou-Mediene, S., Ashby, J., Odenat, L., Mohanesh, J., \& Alamia, H. (in press). The dynamics of post-traumatic growth across different trauma types in a Palestinian sample. Journal of Loss and Trauma: International Perspectives on Stress \& Coping.

Kira, I., Templin, T., Lewandowski, L., Ramaswamy, V., Hammad, A., Mohanesh, J., \& Abdul-Khalek, H. (2012c). Annihilation anxiety, trauma dose and trauma negative appraisal: A new measure for annihilation anxiety. Psychology, 3, 90-99.

Larik, N., Hauf, E., Skeondal, A., \& Solberg, O. (1996). Mental disorder among refugees and the impact of persecution and exile: Some findings from an out-patient population. British Journal of Psychiatry, 196, 726-732.

Lifton, B. (1992). The adopted self: Toward theory of cumulative trauma. Dissertation Abstracts International, 53, 2548.

Lomranz, J. (1990). Long term adaptation to traumatic stress in light of adult development and aging perspectives. In M. P. Stephens, J. Crowther, S. E. Hobfoll, \& D. Tenebaum (Eds.), Stress and coping in later life families (pp. 99-121). New York: Hemisphere.

Laurie, J. (1996). Cumulative trauma: The non-problem problem. Transactional Analysis Journal, 26, 276-283.
Meredith, W. (1993). Measurement invariance, factor analysis and factorial invariance. Psychometrika, 58, 525-543. doi:10.1007/BF02294825

Mollica , R. F., Caspi-Yavin, Y., Bollini, P., Truong, T., Tor, S., \& Lavelle, J. (1992). The harvard trauma questionnaire: Validating a cross-cultural instrument for measuring torture, trauma, and posttraumatic stress disorder. Journal of Nervous and Mental Diseases, 180, 111-116.

Mollica, R., McInnes, K., Poole, C., \& Tor, S. (1998). Dose-effect relationship of trauma to symptoms of depression and PTSD among Cambodian survivors of mass violence. British Journal of Psychiatry, 173, 482-488. doi:10.1192/bjp.173.6.482

Muthén, B. (1989). Multiple group structural modeling with nonnormal continuous variables. British Journal of Mathematical and Statistical Psychology, 42, 55-62. doi:10.1111/j.2044-8317.1989.tb01114.x

Nagy, L. M., Blake, D. D., Dan, E., Riney, S., Mangine, W., Southwick, S. M., Gusman, F., \& Charney, D. S. (1991). Clinician Administered PTSD Scale-Weekly Version (CAPS-2) Reliability, validity, and sensitivity to change. In D. D. Blake (Chair), An update on the Clinician Administered PTSD Scales (CAPS-1 and CAPS-2). Symposium paper presented at the 7 th annual conference of the International Society for Traumatic Stress Studies, Washington DC.

Nishith, P., Mechanic, M., \& Resick. P. (2000). Prior interpersonal trauma: The contribution to current PTSD symptoms in female rape victims. Journal of Abnormal Psychology, 109, 20-25. doi:10.1037/0021-843X.109.1.20

Patrick, M. (1995). The clinical boundaries of post-traumatic stress disorder. Australian and New Zealand Journal of Psychiatry, 29, 385-393. doi:10.3109/00048679509064945

Peretz, T., Baider, L., Ever-Hadani, P., \& De-Nour, A. (1994). Psychological distress in Female cancer patients with Holocaust experience. General Hospital Psychiatry, 16, 413-418. doi:10.1016/0163-8343(94)90117-1

Perez, D. J., Fortuna, L., \& Alegría, M. (2008). Prevalence and correlates of everyday discrimination among US Latinos. Journal of Community Psychology, 36, 421-433. doi:10.1002/jcop.20221

Pieterse, A., Todd, N., Neville, H., \& Carter, R. (2011). Perceived racism and mental health among black American adults a meta-analytic review. Journal of Counseling Psychology, 59, 1-9.

Pinel, E. C. (1999). Stigma consciousness: The psychological legacy of social stereotypes. Journal of Personality and Social Psychology, 76, 114-128. doi:10.1037/0022-3514.76.1.114

Pinto, P., \& Gregory, R. (1995). PTSD with psychotic features. American Journal of Psychiatry, 152, 471.

Oser, E. (1999). Urban adolescents' exposure to violence: The role of cumulative stress, support, and selected moderators in predicting psychological functioning in a school-based sample. Dissertation Abstracts International: Section B: The Sciences \& Engineering, 60, 2357.

Rachman, S. (1980). Emotional processing. Behavior Research and Therapy, 18, 51-60. doi:10.1016/0005-7967(80)90069-8

Richmond, J. M., Elliott, A. N., Pierce, T. W., Aspelmeier, J. E., \& Alexander, A. A. (2009). Polyvictimization, childhood victimization, and psychological distress in college women. Child Maltreatment, 14, 127-147. doi:10.1177/1077559508326357

Silove, D. (1999). The psychosocial effects of torture, mass human rights violations, and refugee trauma: Toward an integrated conceptual framework. Journal of Nervous \& Mental Disease, 187, 200-207. doi:10.1097/00005053-199904000-00002

Silove, D., Sinnerbrink, I., Field, A., Manicavasager, V. et al. (1997). Anxiety, depression and PTSD in asylum-seekers: Associations with pre-migration trauma and post migration stressors. British Journal of Psychiatry, 170, 351-357. doi:10.1192/bjp.170.4.351

Stampfer, H. (1990). "Negative symptoms": A cumulative trauma stress disorder. Australian \& New Zealand Journal of Psychiatry, 24, 516528. doi: $10.3109 / 00048679009062908$

Steenkamp, J., \& Baumgartner, H. (1998). Assessing measurement invariance in cross-national consumer research. Journal of Consumer Research, 25, 78-90. doi:10.1086/209528

Sutker, P., Vasterling, J., Brailey, K., \& Allain, A, (1995). Memory, 
attention, and executive deficits in POW survivors: Contributing biological and psychological factors. Neuropsychology, 9, 118-125. doi:10.1037/0894-4105.9.1.118

Scazufca, M., Menezes, P., Vallada, H., \& Araya, R. (2009). Validity of the self reporting questionnaire-20 in epidemiological studies with older adults Results from the Sao Paulo ageing \& health study. Social Psychiatry and Psychiatric Epidemiology, 44, 247-254. doi:10.1007/s00127-008-0425-y

Terr, L. C. (1991). Childhood traumas: An outline and overview. American Journal of Psychiatry, 148, 10-20.

Turner, S., \& Gorst-Unworth, C. (1990). Psychological sequelae of torture: A descriptive model. British Journal of Psychiatry, 157, 475480. doi:10.1192/bjp.157.4.475

Turner, R., \& Lloyd, D. (1995). Life time traumas and mental health: The significance of cumulative adversity. Journal of Health and Social Behavior, 36, 360-376. doi:10.2307/2137325

Van Der Kolk, B., McFarlane, A., \& Weisaeth, L. (1996). Traumatic stress. New York: Guilford.

Wanous, J., \& Hudy, M. J. (2001). Single-item reliability: A replication and extension. Organizational Research Methods, 4, 361-375. doi: $10.1177 / 109442810144003$

Weathers, F., Keane, T., \& Davidson, J. (2001). The Clinician-Administered PTSD scale: A review of the first ten years of research. De- pression and Anxiety, 13, 132-156. doi:10.1002/da.1029

Weinstien, J., \& del Pozo, E. (2001). Estimates of Michigan's Iraqi refugee population. Unpublished manuscript, Dearborn, MI: Research Design and Consultation.

Wenzel, T., Sibitz, I., Kieffer, W., \& Strobl, R. (1999). Capgras syndrome and functional psychosis in two survivors of torture. Psychopathology, 32, 203-306. doi:10.1159/000029091

Werbert, A., \& Lindbom-Jakobson, M. (1993). The "living dead": Survivors of torture and psychosis. Psychoanalytic Psychotherapy, 7, 163-180. doi:10.1080/02668739300700121

Williams, D., \& Mohammed, S. (2009). Discrimination and racial disparities in health: Evidence and needed research. Journal of Behavioral Medicine, 32, 20-47. doi:10.1007/s10865-008-9185-0

Youngmann, R., Zilber, N., Workneh, F., \& Giel, R. (2008). Adapting the SRQ for ethiopian populations: A culturally-sensitive psychiatric screening instrument. Trans-Cultural Psychiatry, 45, 566-589. doi: $10.1177 / 1363461508100783$

Zimmerman, M., Young, D., Chelminski, I., Dalrymple, K., \& Galione, J. (2012). Overcoming the problem of diagnostic heterogeneity in applying measurement-based care in clinical practice: The concept of psychiatric vital signs. Comprehensive Psychiatry, 53, 117-124. doi:10.1016/j.comppsych.2011.03.004 


\section{A. KIRA ET AL.}

\section{Appendix}

Cumulative Trauma disorder scale with Arabic translation

Please indicate how much these statement apply to your condition in the last month; please mark each statement according to the following scale:

(0). Does not apply;

، برجى وضع دائرة أمام كل عبارة حسب مقياس الثدة المتلدج من صفر ألي4

(1) I am not sure;

(2) Somewhat present;

(3) Much present;

(4) Very much present.

\begin{tabular}{|c|c|c|c|c|}
\hline $\begin{array}{l}\text { Does not apply } \\
\begin{array}{c}\text { أبدا } \\
(0)\end{array}\end{array}$ & $\begin{array}{c}\text { I am not sure } \\
\text { غيرك } \\
\text { (1) }\end{array}$ & $\begin{array}{c}\text { Somewhat pre- } \\
\text { sent } \\
\text { أحيانا } \\
\text { (2) }\end{array}$ & $\begin{array}{c}\text { Much present } \\
\text { (3) }\end{array}$ & $\begin{array}{c}\text { Very much present } \\
\text { تموافقا } \\
\text { (4) }\end{array}$ \\
\hline
\end{tabular}

1. I am depressed. أشعر بالكآبة

2. I feel anxious. أشعر بالقلق

3. I feel sick most of the time.

أشعر بالمرض في اغلب الأحيان.

4. I sometimes feel as if I am almost two different people?

أشعر في اغلب الأحيان كما لو أني شخصين مختلفين

5. I sometimes hear voices or saw things that others did not hear or see.

أحيانا أرى أو اسمع أشياء لا يراها أو يسمعها الآخرين

6. I try to avoid people and stay by myself. أرغب في الانعز ال والابتعاد عن الناس.

7. I believe I have enemies that follow me anywhere I go.

أشعر أن لي أعداء بلاحقونتي أينما اذهب.

8. I have decreased memory or concentration.

أشعر بعدم الققرة على التركيز و التذكر.

9. I do not feel that I have enough control over my responses and reactions.

أنتعر بعدم القدرة على التحكم في تصرفاتي وردود فعلي

10. I felt or thought like killing myself

أثشعر أحيانا بالر غبة في التخلص من حياتي.

11. I feel that I am too cruel dealing with my friends and siblings.

أشعر أني قاسى في التعامل مع إخواني وأصدقائي

12. Sometimes I feel like hurting myself.

اشعر بالر غبة في إيذاء نفسي.

13. I felt like abusing drugs, alcohol, or smoking, or started to. أنثعر أحيانا بالر غبة في تعاطي المخدرات أو التنخين أو أنى أتعاطى المخدرات والتخخين

14. I am not functioning in one or more areas in my life, or felt significant decrease in my ability to function. أثتعر بتتاقص كفاءتي في أداء عملي أو علاقاتي مع الناس

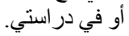

15. I feel apathetic, with no emotion.

أحس بفتور الثعور والعو اطف.

16. I plan to kill myself or I have tried to do it in the past. خططت لكلانتحار , أو حاولت الانتحار في الماضي. 